\title{
Piriformospora indica: A Novel Plant Growth-Promoting Mycorrhizal Fungus
}

\author{
Ajit Varma $\cdot$ Madhunita Bakshi $\cdot$ Binggan Lou $\cdot$ \\ Anton Hartmann · Ralf Oelmueller
}

Received: 19 October 2011 / Accepted: 4 April 2012/Published online: 29 May 2012

(C) NAAS (National Academy of Agricultural Sciences) 2012

\begin{abstract}
Piriformospora indica, a member of the newly created order Sebacinales, is extremely versatile in its mycorrhizal associations and its ability to promote plant growth. $P$. indica is widely distributed as a symptomless root endophyte, and it colonizes members of bryophytes, pteridophytes, gymnosperms and angiosperms. $P$. indica and allied members of Sebacinales have been reported to occur in four continents. The existing literature suggests that the multitude of mycorrhizal interactions in Sebacinales may have arisen from an ancestral endophytic habitat by specialization. Considering their proven beneficial influence on plant growth and their ubiquity, endophytic $P$. indica may have been a previously unrecognized universal hidden force in plant ecosystems. Root colonization by $P$. indica results in an increase in plant growth, early flowering, higher seed yield, alteration in the secondary metabolites, and adaptation to abiotic and biotic stresses. The colonization of roots begins with a biotrophic growth phase, in which living cells are colonized, and continues with a cell death-dependent phase, in which root cells are actively killed by the fungus. The complexity of sebacinalean symbiosis is further enhanced by the presence of endocellular bacteria which may represent significant determinants for a successful outcome of the symbioses. $P$. indica is shown to have enormous bioprotective potential against plant pathogens and insect pests of agricultural and horticultural crops. Recently, decoding of $P$. indica's genome has revealed its potential for application as a plant growth-promoting mycorrhizal fungus for realizing the targeted improvement in the production of crop plants.
\end{abstract}

Keywords Piriformospora indica $\cdot$ Plant growth-promoting mycorrhizal fungus · PGPF

\section{Introduction}

Piriformospora indica was obtained from the rhizosphere soils of the woody shrubs Prosopis juliflora (Swartz) DC. and Zizyphus nummularia (Burm. fil.) Wt. \& Arn. in the sandy desert soils of Rajasthan, India [48, 52]. The fungus is easily

\footnotetext{
A. Varma $(\bowtie) \cdot$ M. Bakshi

Amity Institute of Microbial Technology, Amity University

Uttar Pradesh, Noida 201303, UP, India

e-mail: ajitvarma@aihmr.amity.edu

M. Bakshi

e-mail: bakshi.madhunita@gmail.com

B. Lou

Institute of Biotechnology, Zhejiang University, Hangzhou

310058, People's Republic of China

e-mail: bglou@zju.edu.cn
}

cultivable, lacks host specificity and colonizes roots of many different plants, mostly in an endophytic fashion [49]. $P$. indica is a wide-host root-colonizing endophytic fungus which allows the plants to grow under extreme physical and nutrient stresses. It interacts with a wide range of hosts, including bryophytes, pteridophytes, gymnosperms and a 
large number of mono- and dicot plants [12, 27-29, 31, 37, 49]. The fungus grows inter- and intracellularly, forms pearshaped, auto fluorescent chlamydospores within the cortex of the colonized roots and in the rhizosphere zone, but it does not invade the endodermis and the aerial parts of the plants. The fungus promotes nutrient uptake, allows plants to survive under water, temperature and salt stresses, and confers systemic resistance to toxins, heavy metal ions, insects and pathogenic organisms [10]. Further, it is shown to stimulate excessive production of biomass, early flowering, seed production and a potential microorganism imparting biological hardening to tissue culture-raised plants $[11,52,56]$. This article highlights the important biological and molecular features of the fungus and the potential biotechnological applications as a plant growth-promoting mycorrhizal fungus (PGPF).

\section{Taxonomy}

Taxonomic position of this fungus is determined by molecular methods based on 18S rRNA sequences and by electron microscopy, which suggest that this fungus is related to the Hymenomycetes of the Basidiomycota. Electron microscopy revealed the presence of typical dolipores with continuous non-perforated parenthesomes, which indicated that $P$. indica belongs to the Hymenomycetes (Basidiomycota). Comparison with sequences from the Genbank data base indicated that $P$. indica is closely related to the Rhizoctonia group [49].

Molecular phylogenetic analyses have revealed that $P$. indica is a member of the basidiomycetous order Sebacinales (Basidiomycota: Agaricomycetes) [18, 33, 54]. Until the advent of molecular methods for fungal identification, only a few morphospecies were known from this fungal group. Since then, more and more sebacinoid fungi have been detected as mycobionts of plant roots in molecular ecological studies, and it has become apparent that Sebacinales harbours an enormous biodiversity [55].

Although the exact phylogenetic position of the Sebacinales within the Agaricomycetes is still unclear, it has been shown that they can be divided into two major clades, which have been informally designated as groups A and B (Fig. 1) ([33]; see also [55]). The anamorphic $P$. indica, belongs to group B. Interestingly, $P$. indica is phylogenetically closely related to strain DAR 29830 [55], a multinucleate Rhizoctonia. Basiewicz et al. [3] reported significant differences in the physiological and molecular parameters inferred from morphologically very similar strains of Piriformospora. As a first taxonomic consequence, they have described Piriformospora williamsii as a new member of the so far monotypic genus Piriformospora and show that this genus contains still undescribed species that were recently discovered as endophytes of field-collected specimens of Anthyllis, Medicago, and Lolium in Germany.

The complete $24.97 \mathrm{Mb}$ genome of $P$. indica has been sequenced and confirmed by blast search with highly conserved core genes present in higher eukaryotes $[57,58]$. The sequence analysis has shown that $P$. indica possesses biotroph-associated genomic adaptations, such as lack of genes involved in nitrogen metabolism and a limited potential for damage and destruction shared by symbiotic fungi and obligate biotrophic pathogens. On the other hand, $P$. indica also shares genomic traits with saprotrophic and hemibiotrophic phytopathogenic fungi, such as the presence of an expanded enzyme arsenal which is weakly expressed during the initial biotrophic phase. These and cytological evidences suggest that $P$. indica represents a missing link between decomposer fungi and obligate biotrophic mutualists [58].

Morphological Features

The young mycelia of $P$. indica are white and almost hyaline, but inconspicuous zonations are observed in older cultures. The mycelia are mostly flat and submerged into the substratum. The hyphae are thin walled and of different diameters ranging from 0.7 to $3.5 \mu \mathrm{m}$. The mycelia are often intertwined and overlap each other. In older cultures and on the root surface, hyphae are often irregularly inflated, showing a nodose to coralloid shape, and granulated dense bodies are formed. Hyphae sometimes show anastomosis and are irregularly septated. For this reason, many cells contain more than one nucleus. Chlamydospores are formed from thin-walled vesicles at the tips of the hyphae. The chlamydospores appear singly or in clusters and are distinctive because of their pear-shaped structure. Very young spores have thin, hyaline walls. At maturity, the walls are up to $1.5 \mu \mathrm{m}$ thick, which appear as two layered: smooth and pale yellow. The cytoplasm of the chlamydospores is densely packed with granular materials and usually contains 8-25 nuclei (Fig. 2). Neither clamp connections nor sexual structures are found.

\section{Culture Characteristics}

Piriformospora indica grows best on modified Hill-Käfer synthetic medium $[19,30]$. Under the optimized cultural conditions (inoculum size: $5 \%$; agitation speed: $200 \mathrm{rpm}$; working volume: $30 \%$; initial $\mathrm{pH}$ : 6.5 ; temperature: $30{ }^{\circ} \mathrm{C}$ ), maximum dry cell weight is obtained after 5 days; in 500-ml Erlenmeyer flask, the sporulation starts after 6 days of growth; and maximum spore yield is obtained after 8 days. However, when $P$. indica was grown in a 14-1 bioreactor (Chemap AG, Switzerland) using Hill-Käfer medium maximum, dry cell weight was obtained after $42 \mathrm{~h}$ of growth, the fungus-initiated sporulation after $48 \mathrm{~h}$, and a 


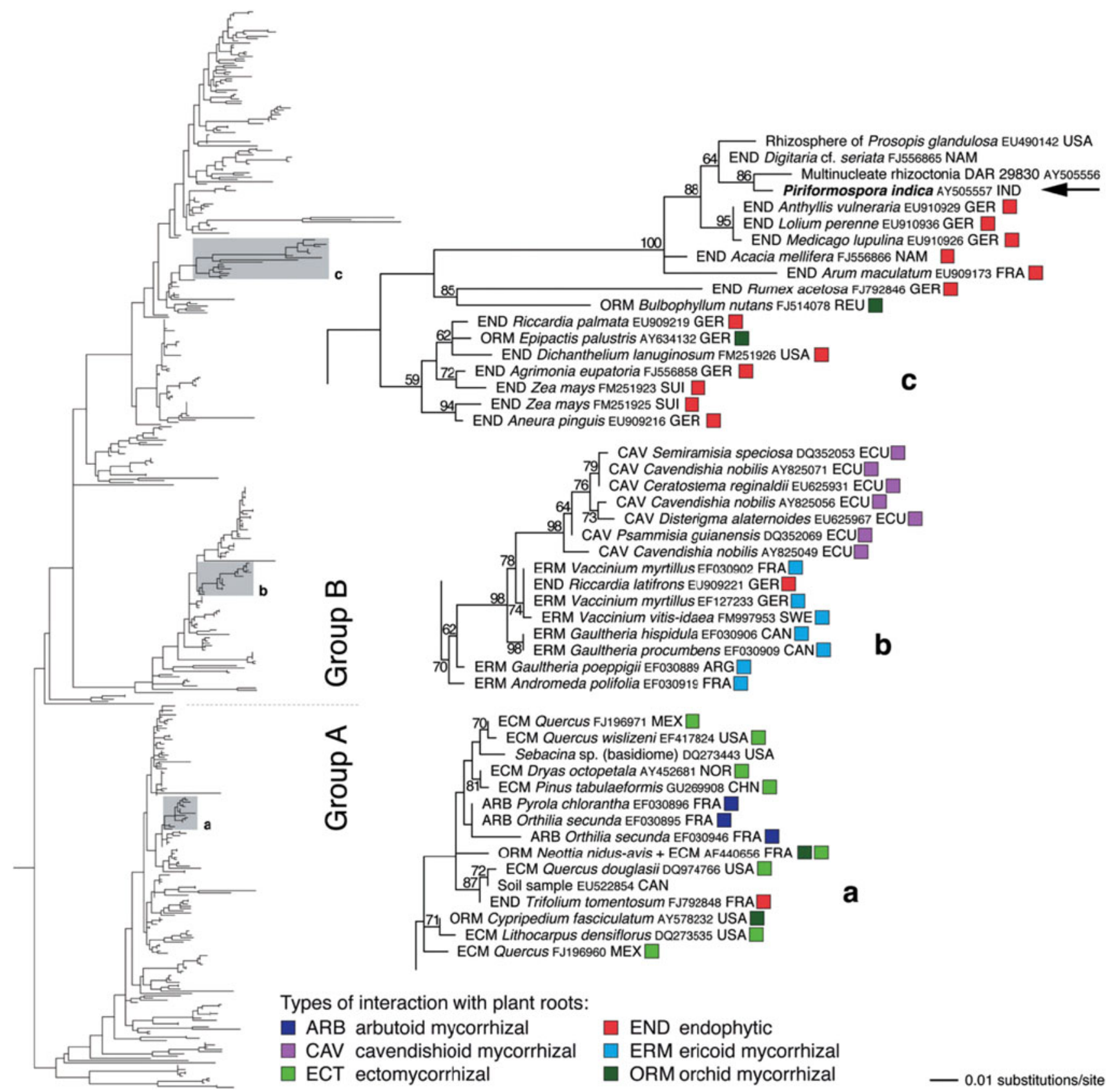

Fig. 1 An overview of the phylogenetic relationships in the Sebacinales, based on a representative sampling of partial nuclear-encoded ribosomal large subunit sequences. Most of the available sequences are from mycobionts detected in plant roots in the field. The alignment was calculated using MAFFT [22]; a phylogenetic hypothesis was constructed using maximum likelihood analysis as implemented in RAxML [42]. Detailed subtrees illustrate the phylogenetic relationships of the three clades highlighted in the full tree (a from Sebacinales group A; b, c from group B); subtree sequences are identified by their GenBank accession numbers. The

spore yield of $9.25 \times 10^{7}$ spores $/ \mathrm{ml}$ was achieved after $60 \mathrm{~h}$ of growth. The early sporulation in this case may be due to rapid consumption of glucose. Owing to more efficient mixing and homogenized fungal suspension, the placement of $P$. indica in clade c is indicated by the arrow. Numbers on the branches are bootstrap support values obtained from 1,000 replicates (only values $\geq 50 \%$ are shown); branch lengths are scaled in terms of the number of expected substitutions per nucleotide. Coloured boxes indicate the type of symbiosis. Country codes used: ARG Argentina; CAN Canada; CHN China; ECU Ecuador; FRA France; GER Germany; GBR Great Britain; IND India; ITA Italy; MEX Mexico; NAM Namibia; NOR Norway; REU Reunion; SUI Switzerland; USA United States of America. For more details of Sebacinales phylogeny, see [33]. (Color figure online)

growth of fungus was faster in the bioreactor and resulted in early depletion of the carbon source and thereby in the early sporulation compared with the batch culture in shake flasks. 

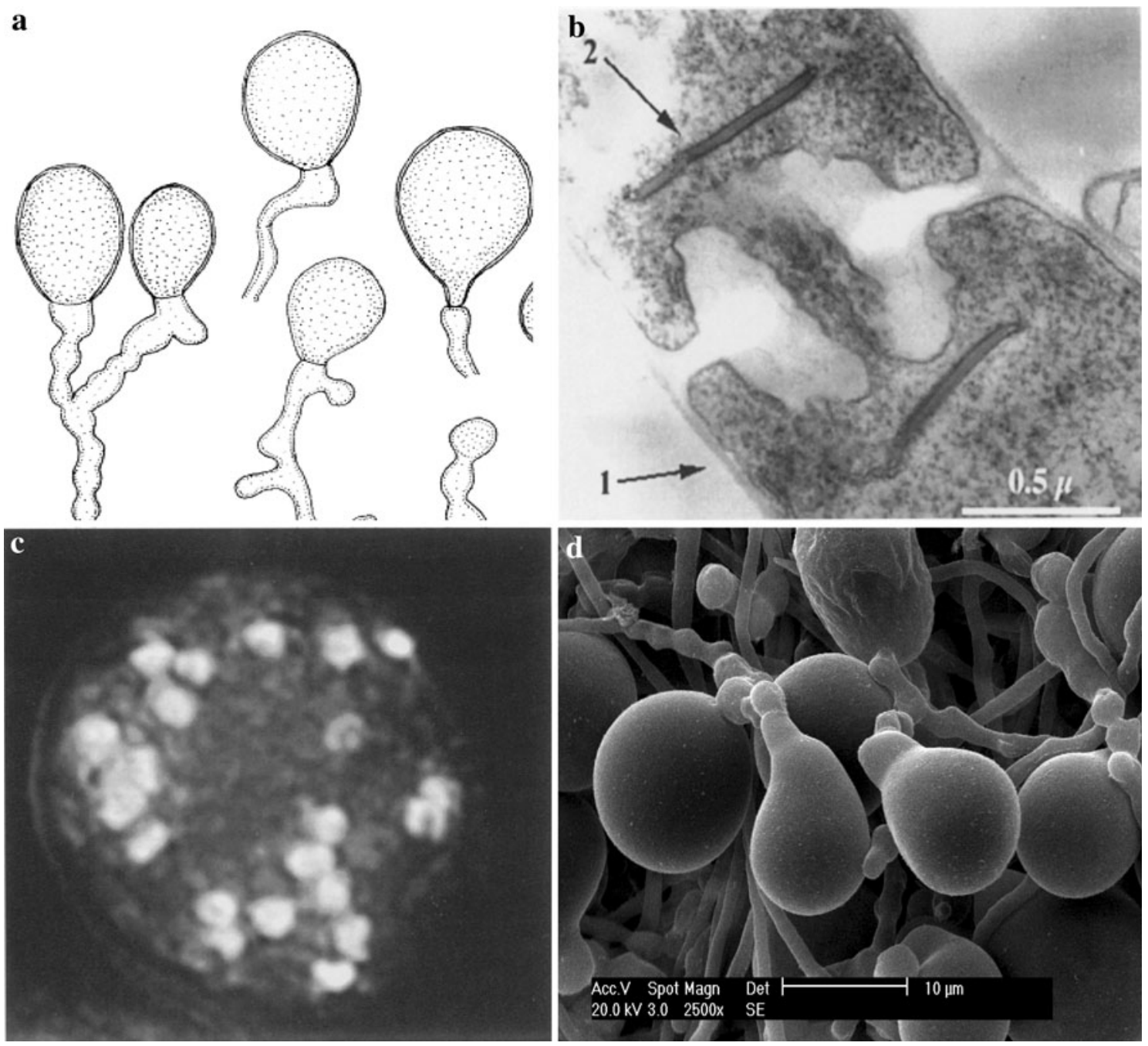

Fig. 2 a Chlamydospores of $P$. indica. b Ultrathin sections of $P$. indica mycelium showing dolipore, parenthesomes (arrow 2) and cell wall (arrow 1). c Nuclei in a chlamydospore. Chlamydospores were stained with DAPI and observed by epifluorescense microscopy.

The pattern of $\mathrm{pH}$ profile was quite similar in all those experiments where complex nitrogen sources were present in the growth medium. The uptake of glucose resulted in acidification of fermentation broth which might be due to generation of acidic metabolites. The growth of the fungus remained unaffected as long as the $\mathrm{pH}$ during the log phase was not reduced below 4.5 [4].

\section{Formulation}

Effective formulation of $P$. indica for use as bioinoculant is prepared in carrier powder (Magnesium sulphite) or vermiculite with $20 \%$ moisture sterilized by autoclaving at $121{ }^{\circ} \mathrm{C}$ temperature and $15 \mathrm{lb} / \mathrm{inch}^{2}$ pressure for $20 \mathrm{~min}$ for three consecutive days. The average particles size is maintained as $50-80$ and $40-70 \mu \mathrm{m}$ for talcum and

Different optical plains were assembled in one picture using the Improvision software package (IMPROVISION, Coventry, UK). d Scanning electron micrograph of chlamydospores of $P$. indica

vermiculite, respectively. The live propagules value is maintained as $10^{9} \mathrm{cfu}[36]$.

\section{Interaction with Plant Growth-Promoting Rhizobacteria and Other Rhizobacteria}

Exploiting the potential of fluorescent Pseudomonads, Serratia spp., Bacillus spp. and Burkholderia spp. to act as crop protectants (biological control agent) has been the focus of many research groups. Their biocontrol capabilities result largely from their ability to produce a battery of antifungal metabolites which also can affect beneficial fungal-root symbioses [34]. On the other hand, Azospirillum and Herbaspirillum spp., for example, which are known as diazotrophic, plant growth-promoting agents or green biofertilizer, are also gaining much importance to 
improve nutrition, growth and yield of crop and energy plants [13]. Research on the cellular and metabolome basis of the interaction of these plant-beneficial bacteria with $P$. indica should contribute to the understanding of the beneficial or deleterious associations between bacteria and fungi in general. The intense interaction between $P$. indica and economically important rhizobacteria is known. While some rhizobacteria could promote growth and root colonization of the fungus or behave neutral in the interaction with $P$. indica, others severely inhibit its development.

\section{Confrontation Assays on Plates}

Stimulatory and inhibitory influences as a result of co-cultivation of $P$. indica with diverse rhizobacteria have been studied in confrontation assays on nutrient agar plates using a collection of strains and mutants. While Pseudomonas putida IsoF promoted the growth of the fungus, most of the Pseudomonas strains, like Ps. fluorescens WS5 and SS101, and the nitrogen-fixing Burkholderia cepacia LA3, Gluconacetobacter sp. Comb19, and Streptomyces lividans SL8 inhibited the growth of $P$. indica (Table 1). The commercially available plant growth-enhancing strain Bacillus amyloliquefaciens FZB42 (Rhizo Plus ${ }^{\mathrm{R}}$, ABITEP, Berlin, Germany) has been investigated to determine the nature of the inhibitory compound. In this bacterium, several lipopeptide and antibiotics are known, and knockout mutants are available $[7,23]$. While the wild type strain FZB42 severely inhibits the growth of $P$. indica, the mutants $\mathrm{CH} 3, \mathrm{AK} 1$ and $\mathrm{AK} 3$, lacking lipopeptide, polyketide synthesis or bacillomycin D production, respectively, had no inhibitory effect. In contrast, the mutant AK2, deficient only in fengyin production, was still inhibitory. This pointed to the fact, that bacillomycin is the most effective inhibitory metabolite in the interaction of FZB42 with $P$. indica. The biocontrol strain Ps. fluorescens SS101 [34] inhibited growth of $P$. indica, while its lipopeptide biosurfactant massetolide A-deficient mutant 10.24 had clearly no inhibitory effect on hyphal growth of $P$. indica. Accordingly, the isolated cyclic lipopeptide massetolide A inhibited the growth of $P$. indica down to 1-10 $\mu \mathrm{g}$ concentrations in the confrontation assay.

\section{Interaction of Rhizobacteria with $\boldsymbol{P}$. indica in Axenic Barley Seedlings}

When $P$. indica is applied to barley roots in an axenic system, root development is seen enhanced already in the seedling stage (Fig. 3a). Selected rhizobacteria that showed stimulation or inhibition of the growth of $P$. indica in the confrontation plate assay influenced also the root growth stimulatory effect of $P$. indica in the gnotobiotic barley
Table 1 Influence of rhizobacteria on growth of $P$. indica

\begin{tabular}{|c|c|c|}
\hline Strains & Source & Impact \\
\hline Herbaspirillum frisingense GSF30 ${ }^{\mathrm{T}}$ & Muenchen & Neutral \\
\hline H. lusitanum $\mathrm{P} 6-12^{\mathrm{T}}$ & Muenchen & Neutral \\
\hline H. seropedicae $\mathrm{Z} 67^{\mathrm{T}}$ & Muenchen & Neutral \\
\hline H. rubrisubalbicans LMG $2286^{\mathrm{T}}$ & Muenchen & Neutral \\
\hline Azospirillum brasilense $\mathrm{Sp} 7^{\mathrm{T}}$ & Muenchen & Neutral \\
\hline A. brasilensis $\mathrm{Sp} 245$ & Muenchen & Neutral \\
\hline Bacillus coagulans NCC235 & New Delhi & Neutral \\
\hline Bacillus subtilis NCC09 & New Delhi & Neutral \\
\hline Pseudomonas putida IsoF & Muenchen & Stimulatory \\
\hline Serratia liquefaciens MG1 & Muenchen & Inhibitory \\
\hline Burkholderia cepacia LA3 & Muenchen/Dharbanga & Inhibitory \\
\hline Ps. fluorescens WS5 & Bangalore & Inhibitory \\
\hline Gluconacetobacter sp. Comb19 & Coimbatore & Inhibitory \\
\hline Streptomyces lividans SL8 & Jena & Inhibitory \\
\hline Streptomyces coelicor A 3(2) & Jena & Inhibitory \\
\hline Bacillus amyloliquefaciens FZB42 & Berlin & Inhibitory \\
\hline Bacillus amyloliquefaciens $\mathrm{FZB} 42$, mutant $\mathrm{CH} 3^{\mathrm{a}}$ & Berlin & No inhibition \\
\hline Bacillus amyloliquefaciens $\mathrm{FZB} 42$, mutant $\mathrm{AK} 1^{\mathrm{b}}$ & Berlin & No inhibition \\
\hline Bacillus amyloliquefaciens $\mathrm{FZB} 42$, mutant $\mathrm{AK} 2^{\mathrm{c}}$ & Berlin & Slight inhibition \\
\hline Bacillus amyloliquefaciens $\mathrm{FZB} 42$, mutant $\mathrm{AK} 3^{\mathrm{d}}$ & Berlin & No inhibition \\
\hline Pseudomonas fluorescens SS101 & Wageningen/Netherlands & Inhibitory \\
\hline Pseudomonas fluorescens SS101, mutant $10.24^{\mathrm{e}}$ & Wageningen/Netherlands & No inhibition \\
\hline
\end{tabular}


Fig. 3 a Root dry weight of axenically grown barley seedlings under the influence of $P$. indica and rhizobacteria A. brasilense Sp245, Serratia liquefaciens MG1 and Ps. putida IsoF (control: not inoculated). b Colonization of barley roots in an axenic system by $P$. indica and Ps. putida IsoF, demonstrated by FISHanalysis and confocal laser scanning microscopy (LSM510, Zeiss Jena, Germany). The fluorescence labelled oligonucleotide probes Eub339 I, II, III-Cy5 (blue in rgb-image) for bacteria (Ps. putida IsoF) and EuK-Cy3 (red in the rgbimage) for $P$. indica were applied [50]. (Color figure online)

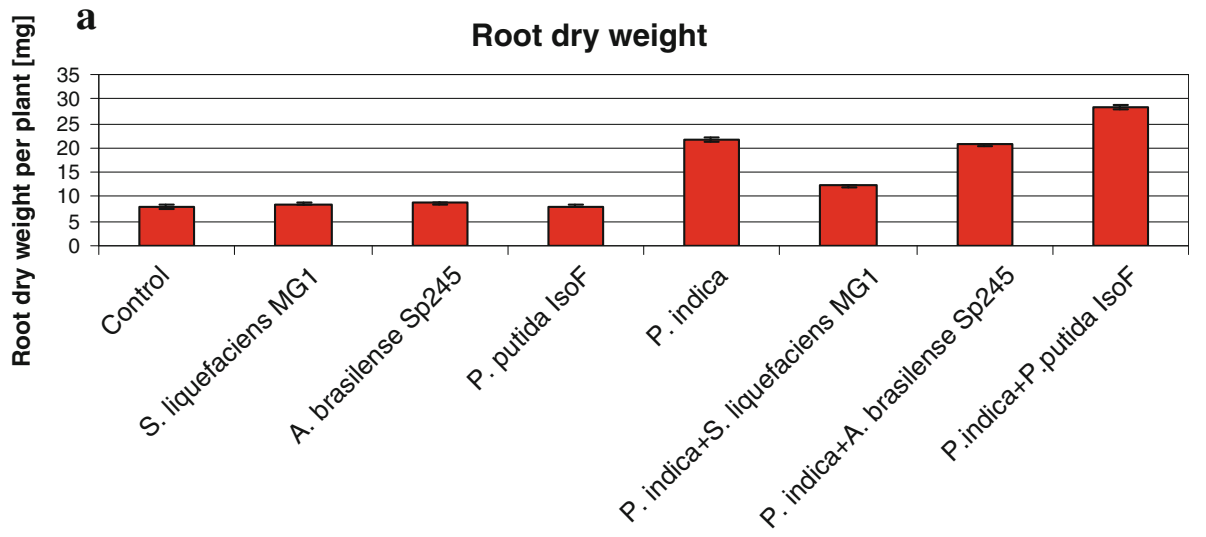

b

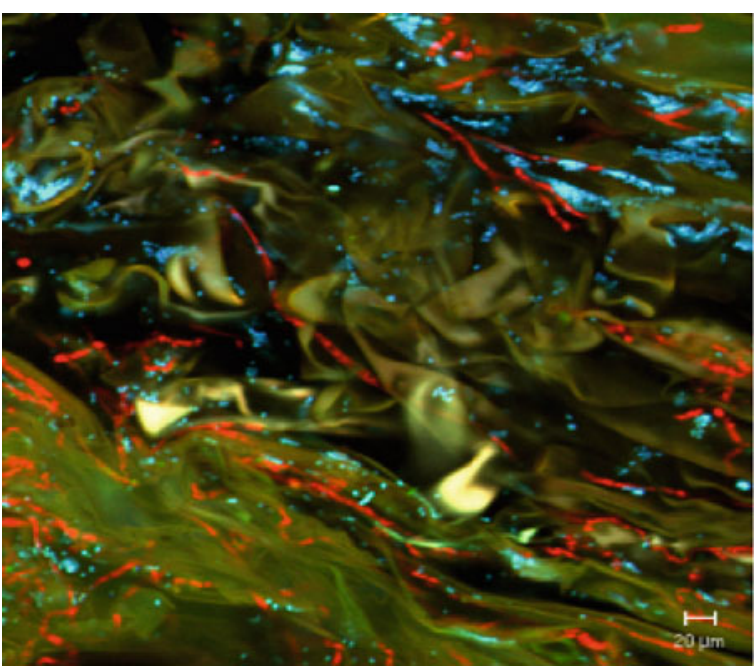

system. While Azospirillum brasilense Sp245 had no effect, Serratia liquefaciens MG1 clearly inhibited, and Pseudomonas putida IsoF enhanced, the root growth stimulation of $P$. indica. FISH-analysis using probes specific for the bacteria and fungi and confocal laser scanning microscopy demonstrated close physical interactions between the Pseudomonas putida IsoF and P. indica [29] (Fig. 3b), while in the case of inhibitory interactions, close contact was rare (not shown).

\section{Structural Changes of $\boldsymbol{P}$. indica Induced by Inhibitory Ps. fluorescens WS5}

In vitro inhibition assays on solid agar medium revealed that Ps. fluorescens WS5 and Burkholderia cepacia LA3 [20] inhibit the growth of $P$. indica. In the presence of $P$. fluorescens WS5, no observable mycelial mat of $P$. indica is produced, the hyphae remain thin, and lysis is observed in some of the hyphae. In addition, a moderate acidification of the medium (from pH 6.5 down to $\mathrm{pH} 5.5-6.0$ ) is observed in $P$. indica control cultures, while in co-culture with $P$. fluorescens $\mathrm{WS} 5$, the $\mathrm{pH}$ is reduced to $\mathrm{pH}<4.0$.
Scanning electron microscopy of $P$. indica showed healthy hyphae with a smooth chitinous cell wall. The fungal hyphae were damaged when the bacterial cells were in direct physical contact with the fungus [50]. Certain dotted substances were released. Transmission electron micrography further unravelled the morphology of the dotted substance released during Ps. fluorescens WS5 interaction. At $28000 \times$ magnification, the Pseudomonastreated hyphae showed the button-like structure with single central dot. This unique structure is approximately of $20-25 \mathrm{~nm}$ in diameter. The nature of these structures remains to be established.

The unit volume of the treated fungus culture was reduced from 20.2 to $11.9 \mu \mathrm{m}^{3}$, where unit length of hyphae was considered $5 \mu \mathrm{m}$, and volume is calculated using formula $\pi r^{2} h$ (where $\pi=3.14, r=$ radius of the hypha, and $h=$ unit length of the hypha). In several micrographs, it was observed that the number of mitochondria varied from 2 to 7 (considering longitudinal as well as transverse sections) per unit volume hyphae without the influence of Ps. fluorescens WS5. In the bacteriatreated hyphae, the number of mitochondria was considerably reduced to $0-3$ per $5 \mu \mathrm{m}^{3}$ hyphal length [9]. 


\section{Metabolome Analysis of $P$. indica}

The inhibitory influence of $B$. cepacia LA3 was more intense (0.9-cm growth diameter) as compared to $P s$. $f u$ orescens WS5 (1.3-cm growth diameter). In the control cultures, $P$. indica covers the entire petri plate, whereas, in the presence of $B$. cepacia LA3, the growth of $P$. indica was completely restricted. A change in the metabolome of the fungal biomass, as influenced by the bacterial metabolites, was investigated using high-resolution mass spectrometry. To enable us investigate a wide range of small molecular weight components, positive electro-spray ionization Fourier transform ion cyclotron resonance mass spectrometry with direct ion infusion (ESI+-FT-ICR-MS) at broad mass range was applied. Owing to the high resolution (100,000-500,000) and high mass accuracy $(<0.5 \mathrm{ppm}$ at $\mathrm{m} / \mathrm{z}$ range of $150-1,000), 3,000-6,000$ peaks were detected from the extract of the biomass. The peaks then were annotated to the metabolites listed in KEGG database applying online software (http://mips.gsf.de/proj/ $\mathrm{mbx} / \sim$ masstrix/) that gives an overview of the possible presented and detectable metabolites within the characterized pathways and could be used for non-targeted metabolome screening, which, however, cannot differentiate the isomers. Since only a few fungal species have been investigated in this manner and $P$. indica has not been characterized in the KEGG database, a model organism had to be selected. The highest matches within the pathways were found, when $S$. cerevisiae was used as a model organism. The metabolome pattern of the methanol extract did not show dependency on the age of the P. indica biomass. Since there was no physical contact between the bacteria and the fungal hyphae, the inhibiting effect was caused by the excreted metabolite(s) of B. cepacia [51].

The number and type of metabolites within the pathways present in S. cerevisiae were compared with the metabolites in the extract of fungal biomass grown with and without the influence of B. cepacia LA3. Out of 110 pathways, 42 were further investigated, since these had more than three annotated metabolites. Changes in the number of annotated metabolites were observed in several pathways, but in some of them, like the phenylalanine metabolism and biosynthesis or sphingolipid metabolism, the metabolites were not influenced by the interaction with B. cepacia LA3.

A decrease in the annotated metabolites of the pentose phosphate and glycolysis was observed in the treated fungi compared with the control indicating a reduction in the activities of these pathways. In contrast, the number of annotated metabolites in the ubiquinone biosynthesis, limonene and pimene degradation, and folate biosynthesis greatly increased under the influence of the inhibitory bacterium.
The diffusible inhibitory metabolites of the B. cepacia LA3 exerted a complex influence on the metabolomic pathways of $P$. indica. Therefore, a mixture of small molecular weight and bioactive components were taken to compare the pathway differences of inhibited growth of the fungus. Saponin was selected as a model component mixture produced by plants. It is a complex mixture of biomolecules like steroids and terpenes having surfactant and inhibitory activity. The growth of $P$. indica grown in medium containing saponin was clearly inhibited, and the suppression was concentration dependent. The suppression of fungal growth was dependent on the concentration of the saponin in the range from 0.1 to $1.0 \%$.

\section{Mechanism of Microbial Interactions}

Several mechanisms, like the production of siderophores, antifungal metabolites, HCN, ammonia and lytic enzymes like chitinases and $\beta-1,3$-glucanases by rhizobacterial isolates, have been implicated in suppression of fungal growth [34]. The differential response of $P$. indica to different rhizobacteria leads us to postulate the existence of an ecological balance among the microbial communities in the rhizosphere/rhizoplane (mycorrhizosphere), which allows diverse microbial functional groups to coexist and share common resources.

The lower diameter of hypha in the P. fluorescens WS5treated sample suggests the fungistatic nature of the 'inhibitory compound'. Spectrofluorimetry, gas chromatography data and mass spectra fragmentation patterns show the $\mathrm{m} / \mathrm{z}$ value to be 416 suggesting thereby that one of the inhibitory substances could be pyoverdine (and its derivatives) - a potent siderophore $[9,14,15]$. Two contrasting observations, i.e. differential response of $P$. indica to the presence of rhizobacteria and its ability to survive in soil and colonize plant roots, led to the hypothesis that microbial communities interact through diffusible metabolites to counteract the inhibitory or stimulatory factor(s), thereby maintaining the delicate balance between diverse soil microorganisms. Concerning the inhibitory effects, antibiotics and lipopeptides produced and excreted by many biocontrol active rhizobacteria were shown to be responsible for the observed inhibition of $P$. indica by the plant growth-enhancing inoculant $B$. amyloliquefaciens FZB42 and the biocontrol rhizobacterium Ps. fluorescens SS101. It was clear from metabolome analysis that glycolysis and the pentose phosphate pathways were deactivated in the treated fungus compared with the control. Since both pathways play important roles in the energy maintenance, a decreased number of metabolites in the pathways responsible for energy production, and in consequence fungal growth, were greatly reduced. To 
investigate if similar mixture has identical influence on the growth of the $P$. indica, saponine was used. The saponine treatment at amounts of $0.1-1 \%$ suppressed the growth of the fungus that-according to the authors' knowledge-has not been reported before.

\section{Genes Involved in Nutrient Uptake and Metabolism}

The endophytic interaction of $P$. indica with plant roots is accompanied by an enormous acquisition of nitrogen and phosphorous from the environment [39, 56]. The growth promotion in Arabidopsis and tobacco seedlings by the fungus is attributed to enhanced nitrate uptake and the expression of the genes for nitrate reductase (Nia2) and the starch-degrading enzyme glucan-water dikinase (SEX1) in roots and shoots [39]. A very high activity of NADHdependent nitrate reductase in the colonized roots results in a massive transfer of nitrogen into the aerial part of the seedlings [21].

Piriformospora indica-responsive Nia2, SEX1, and 2-nitropropane dioxygenase genes are also upregulated in the colonized roots. $P$. indica also stimulates the expression of the $\beta$-glucuronidase gene (uidA) gene under the control of the Arabidopsis nitrate reductase (Nia2) promoter in transgenic tobacco seedlings. Therefore, the growthpromoting effect initiated by $P$. indica is accompanied by a co-regulated stimulation of enzymes involved in nitrate and starch metabolisms [39].

Uptake and transport of phosphorous, with diverse regulatory, structural, and energy transfer roles, are also stimulated by the fungus in the colonized roots of maize [56]. Recent studies have also shown that the sulphur metabolism is stimulated by the fungus. Genes which code for several plastid-localized enzymes required for sulphate reduction are upregulated by $P$. indica in Arabidopsis roots, and gene inactivation studies confirmed that they are required for the benefits to the plants.

\section{Stimulatory Factors}

The analytical HPLC separation of $P$. indica culture supernatant showed seven peaks in the hyphae and one main peak in the culture filtrate. Preparative HPLC analysis of hyphal and culture filtrate showed a major peak identified as benzoic acid. The function of this compound is not clear. Compounds identical to benzoic acid and its analogues (benzoic acid, a-hydroxybenzoic acid, 3-4 di-hydroxybenzoic acid, vanillic acid, cinnamic acid, p-coumaric acid, caffeic acid and ferulic acid) did not show any stimulation on the plants tested. The nature of the stimulatory factors which promote the plant growth is not yet known [2, 29, 49].

\section{Nutrient Transport}

Experiments using ${ }^{32} \mathrm{P}$ have shown that $P$. indica plays an important role for the acquisition of ' $\mathrm{P}$ ' by the roots especially in the arid and semi-arid regions [50]. Cloning and functional analysis of a gene encoding a phosphate transporter $(P i P T)$ from this root endophyte is reported [56]. The PiPT polypeptide belongs to the major facilitator super family (MFS) and exhibits 12 transmembrane helices divided into two halves that are connected by a large hydrophilic loop in the middle. The function of the protein encoded by PiPT was confirmed by complementation of a yeast phosphate transporter mutant. PiPT belongs to high affinity phosphate transporter family (Pht1). To understand the physiological role of $P i P T$, knockdown (KD) transformants of the gene were prepared using electroporation and RNA interference. KD transformants transported a significantly lower amount of phosphate to the host plant than wild-type $P$. indica. Higher amounts of phosphate were found in plants colonized with wild-type $P$. indica than that of non-colonized and plants colonized with KD-PiPT P. indica. These observations suggest that $\mathrm{SP} P \mathrm{PT}$ is actively involved in the phosphate transportation and in turn $P$. indica helps to improve the nutritional status of the host plant [56].

\section{Regulation of Genes Involved in Resistance to Abiotic Stress}

\section{Drought Stress}

Piriformospora indica effectively helps plants to overcome abiotic stress like drought in Arabidopsis thaliana and Chinese cabbage (Brassica campestris L. ssp. Chinensis) [40, 44, 47]. P. indica-colonized A. thaliana plants exposed to drought showed increased drought tolerance and continued to grow, whereas in uncolonized controls, growth was inhibited [40, 41, 47]. Colonized plants had higher chlorophyll content and increased photosynthetic efficiency under drought-stress compared to the uncolonized plants $[40,43]$. Different genes involved in quite diverse processes of drought and other stress responses, i.e. response to dehydration (RD29A), early response to dehydration (ERD1), phospholipase $\mathrm{D} \delta$ (PLD), the transcription factor gene (ANAC072), dehydration-response element-binding protein (DREB2A), salt- and drought-induced ring finger (SDIR1), calcineurin B-like protein (CBL1), CBL-interacting protein kinase (CIPK3), were rapidly upregulated to a higher extent in the leaves of $P$. indica-colonized Arabidopsis seedlings compared to the controls [40]. These genes are involved in quite different cellular processes, starting from phospholipid metabolism at the plasma membrane $(\mathrm{PLD} \delta)$, via cytoplasmic signalling through 
CBL1/CIPK3, control of gene expression in the nucleus (HAT, DREB2A and ANAC072) to cytoplasmic functions associated with RD29A and protein degradation at the endomembrane system (SDIR1) as well as in the plastids (ERD1). The expressions of two ascorbate reductase genes, viz. MDAR2 and DHAR5, are upregulated in the roots and shoots of colonized Arabidopsis seedlings exposed to drought [47]. Monodehydroascorbate reductase (MDAR) and dehydroascorbate reductase (DHAR) are two enzymes of the ascorbate-glutathione cycle that maintain ascorbate, a major antioxidant and radical oxygen scavenger, in its reduced state. Growth and seed production were not promoted in the colonized mdar 2 and dhar 5 mutants indicating that MDAR2 and DHAR5 are crucial for producing sufficient ascorbate to maintain the interaction in a mutualistic state [47]. Thus, $P$. indica confers drought tolerance to Arabidopsis by priming the aerial parts of the plant for an early and high expression of drought-related genes [40, 47].

When $P$. indica-colonized Chinese cabbage plants were exposed to polyethylene glycol to mimic drought stress, the activities of antioxidant enzymes, viz., peroxidases, catalases and superoxide dismutases in the leaves were significantly upregulated within $24 \mathrm{~h}$ [44]. The fungus could retard accumulation of malondialdeyde - a biomarker of oxidative stress, the drought-induced decline in the photosynthetic efficiency and the degradation of chlorophylls and thylakoid proteins in the colonized plants [44]. The expression levels of the drought-related genes $D R E B 2 A$, $C B L 1, A N A C 072$ and $R D 29 A$ were upregulated in the drought-stressed leaves of colonized plants. Furthermore, the CAS mRNA level for the thylakoid membrane associated to $\mathrm{Ca}^{2+}$-sensing regulator (CAS) and the amount of the CAS protein increased in the colonized plants compared with the controls [44]. Therefore, the drought tolerance in Chinese cabbage is associated with the activation of antioxidant enzyme activities, the upregulation of mRNA levels for drought-related proteins, and rapid accumulation of the plastid-localized CAS protein in the leaves of the colonized plants [25, 44].

\section{Low Temperature Tolerance}

Influence of $P$. indica on seed germination under extreme low temperatures was studied in 12 leafy vegetable plants (Table 2), at Leh-Ladakh (DIHAR, DRDO laboratory), India at an altitude of $3,500 \mathrm{~m}$. Within 25 days of plating, $100 \%$ germination was obtained in the seeds of cabbage, endive, Swisschord (Palak), Swisschord (Red), radish and onion treated with $P$. indica (Table 2), whereas, not a single seed germinated in untreated control. The plants treated with $P$. indica grew better compared with the untreated control plants, and after about 3 months' growth in microplots, significant increases in the growth of
Table 2 Percentage germination of seeds of vegetables commonly grown at high altitudes in Leh, Ladakh

\begin{tabular}{lll}
\hline Hosts & $\begin{array}{l}\text { Days after } \\
\text { sowing }\end{array}$ & $\begin{array}{l}\% \text { Increase } \\
\text { in germination }\end{array}$ \\
\hline Cabbage & 25 & 100 \\
Endive & 25 & 100 \\
Swisschord (Palak) & 25 & 100 \\
Swisschord (Red) & 25 & 100 \\
Radish & 25 & 100 \\
Onion & 25 & 100 \\
Carrot & 21 & 84 \\
Cauliflower & 21 & 84 \\
Beetroot & 20 & 80 \\
Peas & 15 & 60 \\
Snowpea & 12 & 48 \\
\hline
\end{tabular}

cabbage, cauliflower and beetroot were recorded (Fig. 4) $[26,50]$. It is important to note that $P$. indica, which is commonly associated with plants growing under extreme hot conditions of Thar desert of western Rajasthan, India also interacted with plants at high altitudes demonstrating unique features which have not been recorded so far (See Patent No. 709/DEL/2011 dated 15th March 2011).

\section{Salt and Nutrient Stress}

It has been shown that this fungus $(P$. indica) can grow even under conditions of high salt concentration of $219.14 \mathrm{mM}$, while its growth was inhibited at salt concentration $438.27 \mathrm{mM}$ (Fig. 5) [8, 25]. P. indica promoted stress tolerance (salt and nutrient) on the co-cultivated tomato (Solanum lycopersicum 'Roma') compared with the control through the activation of antioxidant metabolism, which leads to the accumulation of ascorbate (vitamin C). Tomato fruits borne on the $P$. indica-treated plants maintain lycopene content independent of the growing conditions. Gosal et al. [17] demonstrated that biotization of micropropagated Chlorophytum borivilianum with $P$. indica improves plantlet survival rate: 'P' content, the most important nutrient acquisition. $\mathrm{Cu}, \mathrm{Fe}, \mathrm{Zn}$ and $\mathrm{Mn}$ uptakes are also improved in the plantlets treated with $P$. indica.

Treatment of micropropagated sugarcane plantlets with $P$. indica improved their survival and performance (Table 3). Colonization of inoculated sugarcane roots was extended to $91.8 \%$ in sugarcane cv. CoJ 83 and $92.5 \%$ in cv. CoJ 88 after 4 weeks of growth in the greenhouse. Cane yield and yield components (tillering and cane height) in biohardened field of cv. CoJ 88 were significantly higher than both the non-inoculated micropropagated and noninoculated conventionally propagated sugarcane. Similar observations were made in the ratoon crop too. Iron deficiency was observed in the majority of un-inoculated 
Fig. 4 Piriformospora indica promotes plant growth (under extreme temperature stress at high altitude). a Cabbage; b beetroot (left control; right $P$. indica-treated plants after nearly three months of planting). Interactive experiments were conducted at the Defence Institute of Higher Altitude Research (DIHAR), DRDO, Leh, Ladakh, India at an altitude of $3,300 \mathrm{~m}$
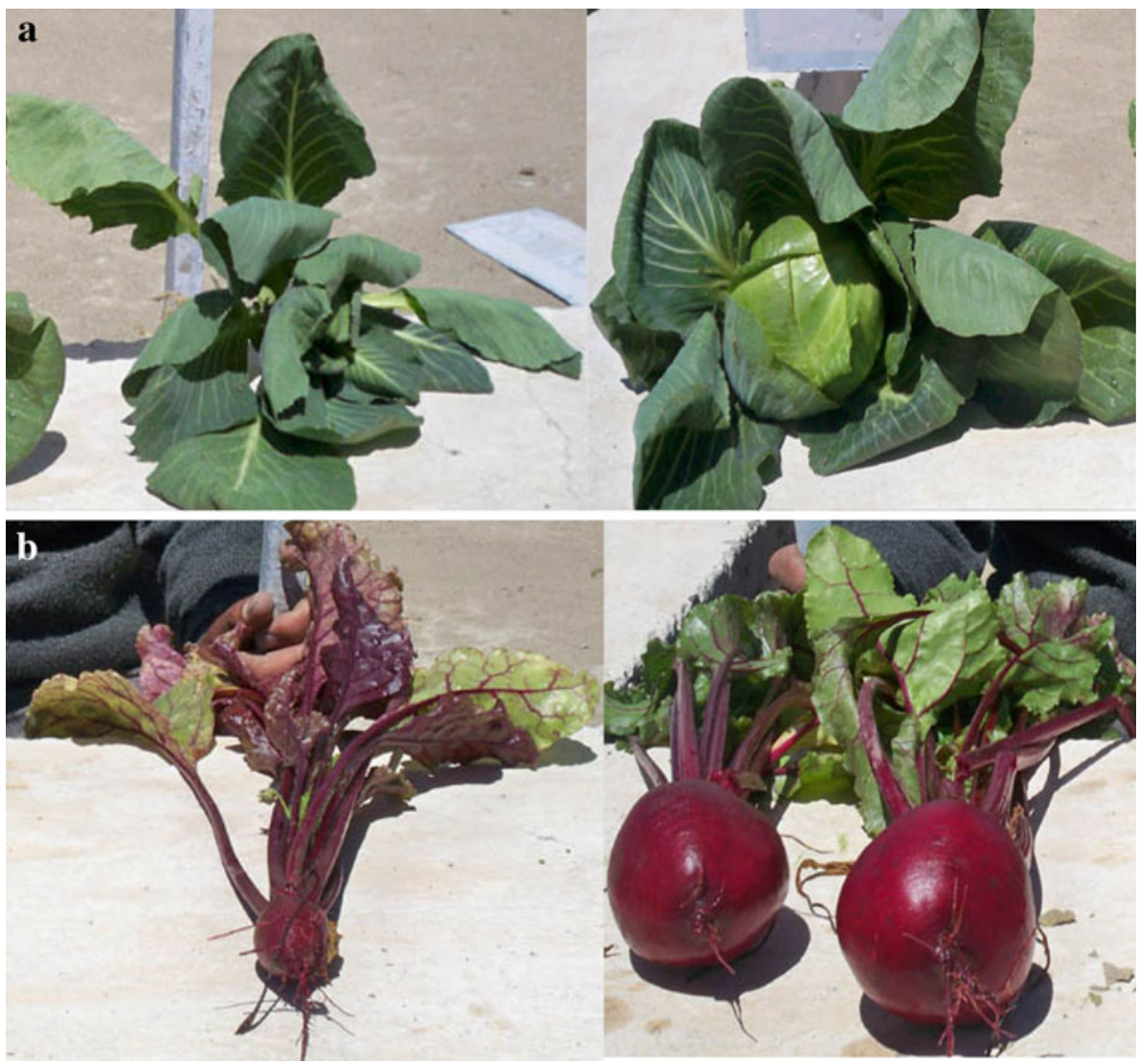
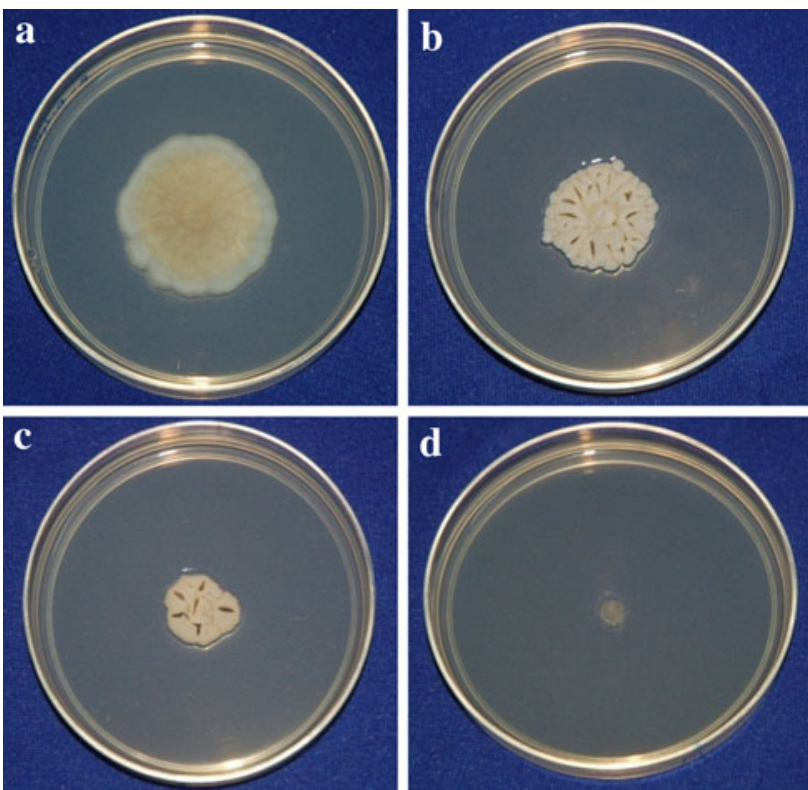

Fig. 5 Growth of $P$. indica on Modified Melin and Norkrans medium in Control and high $\mathrm{NaCl}$ concentrations; a $0.43 \mathrm{mM}$ (Control), b $109.57 \mathrm{mM}$, c $219.14 \mathrm{mM}$, d $438.27 \mathrm{mM}$ (Source: Chordia et al. [8])

ratoon crop plants, but this was not the case with the inoculated ones where the uptake of both $\mathrm{Fe}$ and $\mathrm{Cu}$ was promoted.

\section{Interaction with Plants}

Impact of Fungal Biomass

\section{Cereals}

Piriformospora indica increases nutrient uptake, allows plants to survive under drought, high- and low-temperature and salt stresses, confers systemic resistance to toxins, heavy metal ions and pathogenic organisms, and stimulates growth and seed production. Several other authors [1, 12, $17,24,27-29,35,37,38,40,41,44-49,52,53]$ have reported that the fungus improves the growth and overall biomass production of diverse hosts. A total number of approximately 150 plant species are reported to interact with $P$. indica including agricultural, horticultural, medicinal and other important plants. Oryza sativa, Zea mays, Tridax procumbans, Nicotiana tabacum, Arabidopsis thaliana and Brassica oleracea var capitata plants have been shown to have improved seed germination and an increase in seed formation.

Many plants, viz. Oryza sativa, Zea mays, Phaseolus vulgaris, Tridax procumbans, Abrus precatorius, Solanum nigrum, Brassica oleracea var capitata, Brassica nigra, Nicotiana tabbacum, Saccharum officinarum, Lagenaria sp. and Spinacea oleracea, have shown better plant growth 
Table 3 Interaction of $P$. indica with Saccharum officinarum (var. CoJ 88), in a field trial at Punjab Agricultural University, Ludhiana (courtesy, Dr. S. K. Gosal)

\begin{tabular}{lcclllll}
\hline Treatments & $\begin{array}{l}\text { Tiller number/ } \\
\text { clump }\end{array}$ & $\begin{array}{l}\text { Cane number/ } \\
\text { clump }\end{array}$ & $\begin{array}{l}\text { Cane height } \\
(\mathrm{cm})\end{array}$ & $\begin{array}{l}\text { Cane girth } \\
(\mathrm{cm})\end{array}$ & $\begin{array}{l}\text { Brix (Sugar } \\
\text { content) }\end{array}$ & $\begin{array}{l}\text { Weight per } \\
\text { clump (kg) }\end{array}$ & $\begin{array}{l}\text { Weight per } \\
\text { plot }(\mathrm{kg})\end{array}$ \\
\hline Control & 9.27 & 8.10 & 179 & 2.22 & 18.35 & 6.50 & 122.2 \\
P. indica & 17.2 & 15.90 & 191 & 2.21 & 21.40 & 7.34 & 138.3 \\
CD $(5 \%)$ & 2.59 & 2.51 & NS & NS & 1.99 & NS & 2.39 \\
\hline
\end{tabular}

Fig. $6 P$. indica promotes growth of medicinally important plants under control and field conditions. a Bacopa monniera seedlings showing better growth in medium co-inoculated with P. indica (right flask) [32]; b Artemisia annua showed good growth in field plots treated with P. Indica (right) at Panchmarhi, Madhya Pradesh b

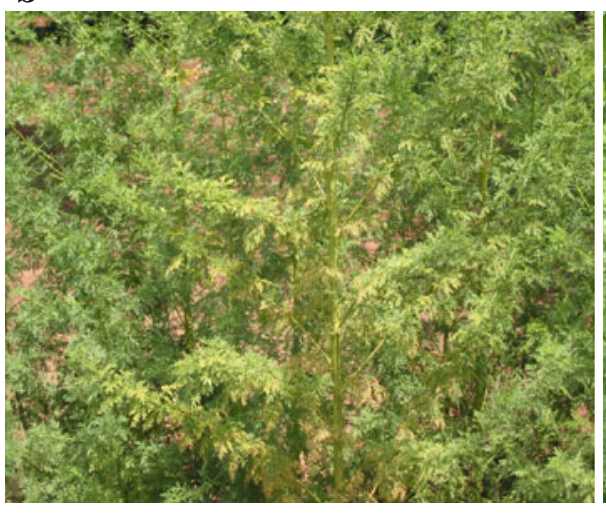

Control $\mathbf{a}$

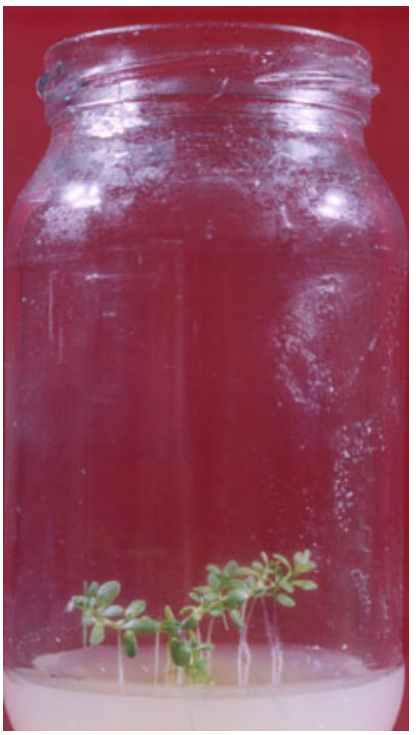

Control

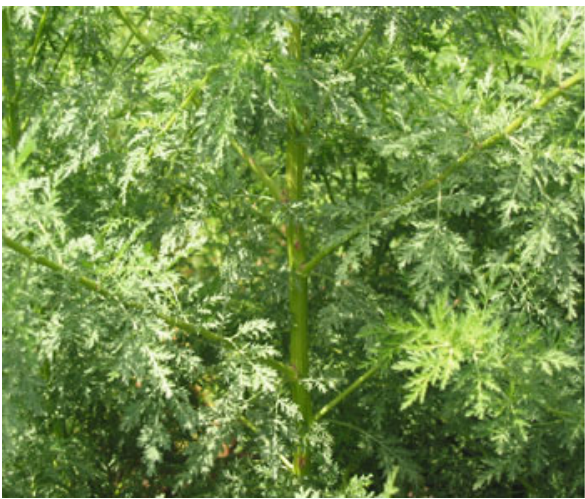

$P$. indica treated with increased biomass production [31]. P. indica-colonized roots show a higher development compared to the control plants at the initial stages of growth, as suggested by earlier expression of developmentally regulated genes [53]. Kumar et al. [24] have shown that maize roots inoculated with $P$. indica show enhanced growth response by the colonization of the exterior root cortex. This fungus also promotes the growth of several tropical legumes (Cicer arietinum, Phaseolus aureus, P. mungo, Pisum sativum and Glycine max) $[49,50]$
Medicinal Plants

Piriformospora indica interacts closely with medicinal plants Artemisia annua, Bacopa monniera, Abrus precatorius, Stevia rebaudiana, Linum album, Trigonella foenumgraecum, Coleus forskohlii, Spilanthes calva, Withania somniferra, Chlorophytum borivilianu, Tridax procumbens, Curcuma longa, Podophyllum peltatum, Azatarichta indica, Foeniculum vulgare, Oscimum sanctum [10, 11, 16, 27]. Some of the important medicinal plants which have been 
reported to beneficially interact with the fungus are shown in Fig. 6. The secondary metabolite contents of all these medicinal plants are found to increase several folds because of their interaction with $P$. indica. The fungus remained neutral and did not colonize the roots of Naga chilli (Capsicum chinense), which was considered as the hottest chilly of the world (557,000 Scoville units, http.//chilly.in/ Indian_chilli_varieties.htm) primarily growing in the North Eastern region of India [50]. Root colonization resulted in early flowering in the plants tested, like in Coleus forskohlii, bottle gourd and Nicotiana tabacum (Fig. 7).

In another study, co-cultivation of live fungal cells with hairy roots of medicinal plant Linum album reduced the growth of hairy roots. Despite reduction in hairy root biomass, an enhancement in lignin content was observed. The hairy root cultures co-cultivated with $1-5 \mathrm{~g} / \mathrm{l}$ fungal biomass at days 10-13, all achieved a higher podophyllotoxin (PT) and 6-methoxypodophyllotoxin (6-MPT) content (mg/ $\mathrm{g}$ ) in the roots other than in the fungus-free control culture. The highest increase in PT content $(8.48 \mathrm{mg} / \mathrm{g})$ and 6-MPT content $(3.78 \mathrm{mg} / \mathrm{g})$ was obtained when a fungal concentration of $2.0 \mathrm{~g} / \mathrm{l}$ was added to a growing hairy root cultures of $L$. album on 12th day, i.e. for exposure time of $48 \mathrm{~h}$. The same fungal concentration for the same duration resulted in maximum improvement by 2.1 -fold in PT concentration and 2.5-fold in 6-MPT concentrations, respectively $[6,36]$.

\section{Impact of Fungal Culture Filtrate}

The culture filtrate of the mycelium contains fungal exudates, minerals, hormones, enzymes, proteins, etc. [2, 49, 52]. In vitro experiments have shown that even very small amounts $(2.5 \mathrm{ml} / \mathrm{l}$ of medium $)$ of culture filtrate are sufficient to promote root and shoot growth. In vitro interaction experiments were tested for Triticum aestivum, Cicer arietinum, Phaseolus vulgaris (Fig. 8a), Brassica campestris
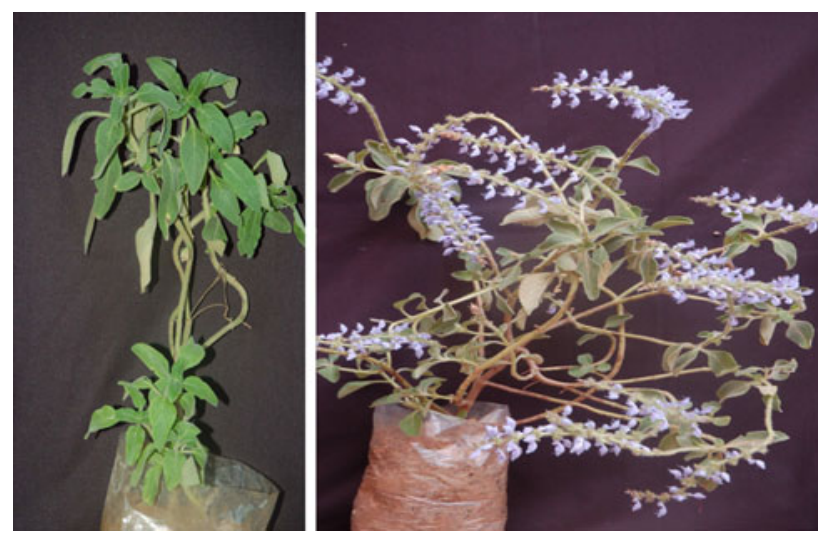

Fig. 7 Piriformospora indica is shown to induce early flowering in Coleus forskohlii; the plant on the right was treated with $P$. indica and Broccoli. The culture filtrate is effective in breaking the dormancy, seed germination and enhancement of the seedlings. This study was repeated in green house, employing pot experiments: 15-day-old seedlings of Zea mays, Brassica oleracea and Helianthus annuus were transferred to plastic pots containing vermiculite (autoclaved) and sand (acid washed) in the ratio of 3:1. An amount of $15 \mathrm{ml}$ freshly eluted $P$. indica culture filtrate was applied to each pot containing one kilogram of substratum. Equal amount of sterile Hill-Käefer medium was added to control. Increases in the root and shoot lengths and plant biomass were observed in the $P$. indica-treated hosts (Fig. 8b) [5].

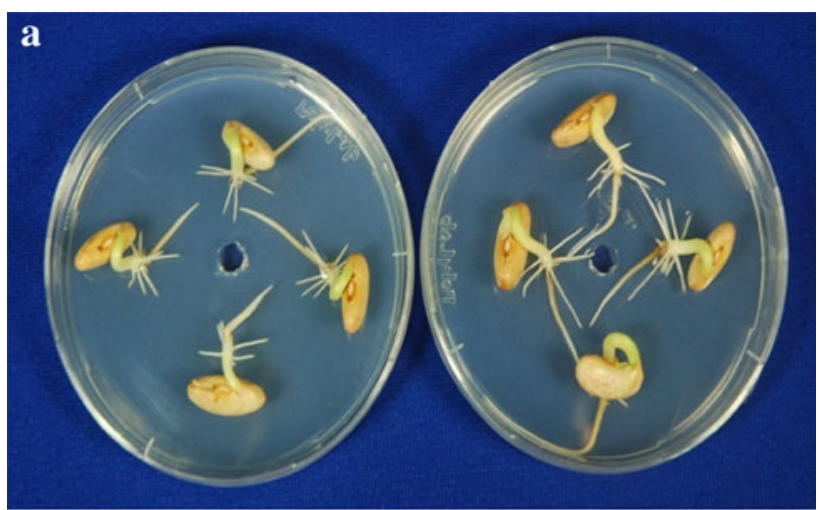

b

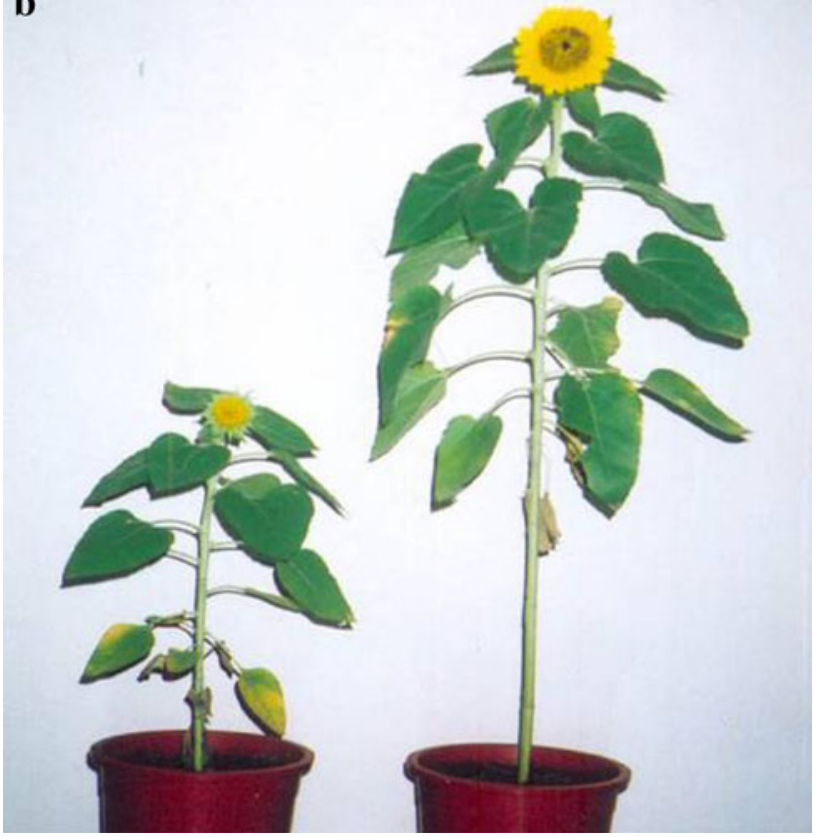

Fig. 8 Promotion of plant growth by $P$. indica culture filtrates. a Improvement in the germination of Phaseolus vulgaris seeds treated by placing $15-\mu 1$ sterile culture filtrate of $P$. indica in the central well (right), compared with sterile water control (left). b Improved growth of $H$. annuus plant treated with $15 \mathrm{ml}$ of sterile $P$. indica culture filtrate (right) compared with the control plant (left) 


\section{Conclusion and Future Prospective}

Piriformospora indica is a well-established symbiont, which benefits plant growth and increases the resistance against pathogens in a broad range of host plants. This study has special significance as the fungus is being exploited for biotechnological applications in the area of agriculture, forestry, arboriculture and flori-horticulture in field, as well as hydroponics cultivation of several vegetables and aromatic hosts. For a possible combined application of $P$. indica with plant growth-promoting rhizobacteria, it has to be tested beforehand so that an inhibitory effect of these rhizobacteria on $P$. indica does not occur. Concerning its beneficial nature, $P$. indica and allied members have considerable potential as bio-control agents and plant-growth promoters. Special efforts should therefore be made to define the molecular and biochemical bases of symbioses and their physiological effects on crop plants, as it is a prerequisite for the introduction of the fungus to different cropping systems. $P$. indica has been extremely valuable in understanding the orchestration of root innate immunity. In particular, the Arabidopsis $-P$. indica system allows for a comparison between root and leaf innate immunities. Further, one may gain an insight into how roots discriminate between pathogens and mutualists. Considering its immune suppressive capacities, $P$. indica might also represent a unique tool to uncover the points of plant innate immunity. The recently accomplished annotation of the $P$. indica genome will undoubtedly support all research efforts related to $P$. indica, but also to other mutualistic plant-colonizing fungi. Moreover, we have just established a stable barley root transformation system that allows the fast and robust analysis of $P$. indica protein functions in all aspects of root development, as well as abiotic stress tolerance and biotic interactions in crop plants.

Acknowledgments The first author is thankful to ICAR, DRDO and DBT for partial funds. The authors are also thankful to I. Sherameti, S. Tripathi, R. Prasad, A. Das, M. Sharma, J. M. Johnson M. Arora, K. Rastogi, A. Agrawal, P. Chordia, A. C. Kharkwal, U. S. Bagde, V. S. Bisaria, C. P. Upadhyaya, P. S. Won, Youyuan Chen, Jie Ma, Ashok Adya, Lixing Zhang, M. K. Meghvanshi, S. K. Gosal, R. B. Srivastava, A. K. Johri, Narendra Tuteja, Philippe Schmitt-Kopplin, Agnes Fekete and C. Cruz for providing relevant information and going through the manuscript.

\section{References}

1. Achatz B, Rüden SV, Andrade D, Neumann E, Kühnemann JP, Kogel KH, Philipp F, Waller F (2010) Root colonization by Piriformospora indica enhances grain yield in barley under diverse nutrient regimes by accelerating plant development. Plant Soil 33:7-59

2. Adya AK, Gautam A, Lixing Z, Varma A (2012) Characterisation of Piriformospora indica culture filtrate: protocol. In: Oelmueller
R, Tripathy S, Kost G, Varma A (eds) Sebacinales. Springer, Germany, in press

3. Basiewicz M, Weiss M, Kogel KH, Langen G, Zorn H, Zuccaro A (2012) Molecular and phenotypic characterization of Sebacina vermifera strains associated with orchids, and the description of Piriformospora williamsii sp. nov. Fungal Biol 116:204-213

4. Bagde US, Prasad R, Varma A (2010) Mass cultivation of Piriformospora indica in new Brumswick fermentor and its formulation as biofertilizer. Asian J Microb Biotechnol 12:911-916

5. Bagde US, Prasad R, Varma A (2011) Influence of culture filtrate of Piriformospora indica on growth and yield of seed oil in Helianthus annuus. Symbiosis 53:83-88

6. Baldi A, Jain A, Gupta N, Srivastava AK, Bisaria VS (2008) Coculture of arbuscular mycorrhiza-like fungi (Piriformospora indica and Sebacina vermifera) with plant cells of Linum album for enhanced production of podophyllotoxins: a first report. Biotechnol Lett 30:1671-1677

7. Chen XH, Vater J, Piel J, Franke P, Scholz R, Schneider K, Koumoutsi A, Hitzeroth G, Grammel N, Strittmatter AW, Gottschalk G, Süssmuth RD, Borriss R (2007) Structural and functional characterization of three polyketide synthase gene clusters in Bacillus amyloliquefaciens FZB42. J Bacteriol 188:4024-4036

8. Chordia P (2011) Salt stress on axenic growth of Piriformospora indica. M.Phil Thesis, Amity University, Uttar Pradesh

9. Das A, Prasad R, Srivastava A, Pham HG, Bhatnagar K, Varma A (2007) Microbial siderophores. In: Varma A, Chincholkar SB (eds) Fungal siderophores: structure, functions and regulation. Springer, Heidelberg, pp 1-35

10. Das A, Sheramati I, Varma A (2012) Contaminated soils: physical, chemical and biological components. In: Varma A, Kothe E (eds) Bio-geo interactions in metal-contaminated soils. Springer, Heidelberg, pp 1-16

11. Das A, Kamal S, Shakil Najam A, Sherameti I, Oelmüller R, Dua M, Tuteja N, Johri Atul K, Varma A (2012) The root endophyte fungus Piriformospora indica leads to early flowering, higher biomass and altered secondary metabolites of the medicinal plant, Coleus forskohlii. Plant Signal Behav 7:1-10

12. Fakhro A, Andrade-Linares DR, von Bargen S, Bandte $M$, Büttner C, Grosch R, Schwarz D, Franken P (2009) Impact of Piriformospora indica on tomato growth and on interaction with fungal and viral pathogens. Mycorrhiza 20:191-200

13. Franche C, Lindström K, Elmerich C (2009) Nitrogen-fixing bacteria associated with leguminous and non-leguminous plants. Plant Soil 321:35-59

14. Fuchs R, Budzikiewicz H (2000) Structural studies of pyoverdines with cyclopeptidic substructures by electrospray ionization and collision induced fragmentation. Spectroscopy 14:229-246

15. Fuchs R, Budzikiewicz H (2001) Structural studies of pyoverdines by mass spectrometry. Curr Org Chem 5:265-288

16. Goltapeh ME, Danesh YR (2006) Pathogenic interactions between Trichoderma species and Agaricus bisporus. J Agric Technol 2:29-37

17. Gosal SK, Karlupia A, Gosal SS, Chhibba IM, Varma A (2010) Biotization with Piriformospora indica and Pseudomonas fuorescens improves survival rate, nutrient acquisition, field performance and saponin content of micropropagated Chlorophytum sp. Indian J Biotechnol 9:289-297

18. Hibbett DS, Binder M, Bischoff JF, Blackwell M, Cannon PF, Eriksson OE, Huhndorf S, James T, Kirk PM, Lücking R, Lumbsch HT, Lutzoni F, Matheny PB, McLaughlin DJ, Powell MJ, Redhead S, Schoch CL, Spatafora JW, Stalpers JA, Vilgalys R, Aime MC, Aptroot A, Bauer R, Begerow D, Benny GL, Castlebury LA, Crous PW, Dai Y-C, Gams W, Geiser DM, Griffith GW, Gueidan C, Hawksworth DL, Hestmark G, Hosaka $\mathrm{K}$, Humber RA, Hyde KD, Ironside JE, Kõljalg U, Kurtzman CP, Larsson K-H, Lichtwardt R, Longcore J, Miadlikowska J, Miller 
A, Moncalvo J-M, Mozley-Standridge S, Oberwinkler F, Parmasto E, Reeb V, Rogers JD, Roux C, Ryvarden L, Sampaio JP, Schüßler A, Sugiyama J, Thorn RG, Tibell L, Untereiner WA, Walker C, Wang Z, Weir A, Weiss M, White MM, Winka K, Yao Y-J, Zhang N (2007) A higher-level phylogenetic classification of the fungi. Mycol Res 111:509-547

19. Hill TW, Käfer E (2001) Improved protocols for aspergillus medium: trace elements and minimum medium salt stock solutions. Fungal Genet News Lett 48:20-21

20. Jha B, Thakur MC, Gontia I, Albrecht V, Stoffels M, Schmid M, Hartmann A (2009) Isolation, partial identification and application of diazotrophic rhizobacteria from traditional Indian rice cultivars. Eur J Soil Biol 45:62-72

21. Johnson JM, Sherameti I, Ludwig A, Nongbri PL, Sun C, Lou B, Varma A, Oelmüller R (2011) Protocols for Arabidopsis thaliana and Piriformospora indica co-cultivation-a model system to study plant beneficial traits. J Endocytobiosis Cell Res 101-113

22. Katoh K, Toh H (2008) Recent developments in the MAFFT multiple sequence alignment program. Brief Bioinform 9: 286-298

23. Koumoutsi A, Chen X-H, Vater J, Borriss R (2007) DegU and YczE positively regulate the synthesis of Bacillomycin D by Bacillus amyloliquefaciens strain FZB42. Appl Environ Microbiol 73:6953-6964

24. Kumar M, Yadav V, Tuteja N, Johri AK (2009) Antioxidant enzyme activities in maize plants colonized with Piriformospora indica. Microbiology 155:780-790

25. Kumar M, Sharma R, Jogawat A, Singh P, Dua M, Gill SS, Trivedi DK, Tuteja N, Varma AK, Oelmueller R, Johri AK (2012) Piriformospora indica, a root endophytic fungus, enhances abiotic stress tolerance of the host plant. In: Tuteja N, Gill SS, Tiburcio AF, Tuteja $\mathrm{R}$ (eds) Improving crop resistance to abiotic stress. Wiley-Blackwell, Weinheim, pp 543-548

26. Murugan P (2011) Enhancing winter vegetable production in greenhouse of cold arid desert of Ladakh by inoculation of Piriformospora indica. DRDO Technology Spectrum, pp 164-170

27. Oelmüller R, Sherameti I, Tripathi S, Varma A (2009) Piriformospora indica, a cultivable root endophyte with multiple biotechnological applications. Symbiosis 49:1-17

28. Peškan-Berghöfer T, Shahollari B, Giong PH, Hehl S, Markert C, Blanked V, Kost G, Varma A, Oelmüller R (2004) Association of Piriformospora indica with Arabidopsis thaliana roots represents a novel system to study beneficial plant-microbe interactions and involves early plant protein modifications in the endoplasmic reticulum and at the plasma membrane. Physiol Plant 122: 465-477

29. Pham GH, Kumari R, Singh A, Sachdev M, Prasad R, Kaldorf M et al (2004) Axenic cultures of Piriformospora indica. In: Varma A, Abbott L, Werner D, Hampp R (eds) Plant surface microbiology. Springer, Germany, pp 593-616

30. Pham HG, Kumari R, Singh A, Malla R, Prasad R, Sachdev M, Kaldorf M, Buscot F, Oelmueller R, Hampp R, Saxena AK, Rexer K-H, Kost G, Varma A (2004) Axenic cultures of Piriformospora indica. In: Varma A, Abbott LK, Werner D, Hampp R (eds) Plant surface microbiology. Springer, Germany, pp 593-613

31. Prasad RP (2008) Studies on interaction between symbiotic fungus (Piriformospora indica), rhizobacteria and selected plants. $\mathrm{PhD}$ Thesis, Merrut University, India

32. Prasad RP, Bagde US, Pushpangadan P, Varma A (2008) Bacopa monniera $L$. Pharmological aspects and case study involving $P$. indica. Int J Integr Biol 3:100-110

33. Qiang X, Weiss M, Kogel KH, Schäfer P (2012) Piriformospora indica - a mutualistic basidiomycete with an exceptionally large plant host range. Mol Plant Pathol. doi:10.1111/J.1364-3703. 2011.00764.X
34. Raajimakers JM, Paulitz TC, Steinberg C, Alabouvette C, Moenne-Loccoz Y (2009) The rhizosphere. A playground and battlefield for soilborne pathogens and beneficial microorganisms. Plant Soil 321:341-361

35. Sahay NS, Varma A (1999) Piriformospora indica: a new biological hardening tool for micropropagated plants. FEMS Microbiol Lett 181:297-302

36. Sarma MVRK, Kumar V, Saharan K, Srivastava R, Sharma AK, Prakash A, Sahai V, Bisaria VS (2011) Application of inorganic carrier-based formulations of fluorescent pseudomonads and Piriformospora indica on tomato plants and evaluation of their efficacy. J Appl Microbiol 111:456-466

37. Shahollari B, Varma A, Oelmüller R (2005) Expression of a receptor kinase in Arabidopsis roots is stimulated by the basidiomycete Piriformospora indica and the protein accumulates in Triton X-100 insoluble plasma membrane microdomains. J Plant Physiol 162:945-958

38. Shahollari B, Vadassery J, Varma A, Oelmüller R (2007) A leucine rich repeat protein is required for growth promotion and enhanced seed production mediated by the endophytic fungus Piriformospora indica in Arabidopsis thaliana. Plant $\mathrm{J}$ 50:1-13

39. Sherameti I, Shahollari B, Venus Y, Altschmied L, Varma A, Oelmüller R (2005) The endophytic fungus Piriformospora indica stimulates the expression of nitrate reductase and the starch-degrading enzyme glucan-water dikinase in tobacco and Arabidopsis roots through a homeodomain transcription factor which binds to a conserved motif in their promoters. J Biol Chem 280:26241-26247

40. Sherameti I, Tripathi S, Varma A, Oelmüller R (2008) The rootcolonizing endophyte Pirifomospora indica confers drought tolerance in Arabidopsis by stimulating the expression of drought stress-related genes in leaves. Mol Plant Microbe 21:799-807

41. Sherameti I, Venus Y, Drzewiecki C, Tripathi S, Dan VM, Nitz I, Varma A, Grundler FM, Oelmüller R (2008) PYK10, a $\beta$-glucosidase located in the endoplasmic reticulum, is crucial for the beneficial interaction between Arabidopsis thaliana and the endophytic fungus Piriformospora indica. Plant J 54:428-439

42. Stamatakis A (2006) RAxML-VI-HPC: maximum likelihoodbased phylogenetic analyses with thousands of taxa and mixed models. Bioinformatics 22:2688-2690

43. Strasser RJ, Tsimilli-Michael M, Dangre D, Rai M (2007) Biophysical phenomics reveals functional building blocks of plant system biology: a case study for the evaluation of the impact of mycorrhization with Piriformospora Indica. In: Varma, Oelmueller (eds) Advanced techniques in soil microbiology. Springer, Heidelberg, pp 319-338

44. Sun C, Johnson JM, Cai D, Sherameti I, Oelmüller R, Lou B (2010) Piriformospora indica confers drought tolerance in Chinese cabbage leaves by stimulating antioxidant enzymes, the expression of drought-related genes and the plastid localized CAS protein. J Plant Physiol 167:1009-1017

45. Vadassery J, Ritter C, Venus Y, Camehl I, Varma A, Shahollari B, Novak O, Strnad M, Ludwig-Muller J, Oelmüller R (2008) The role of auxins and cytokinins in the mutualistic interaction between Arabidopsis and Piriformospora indica. Mol Plant Microbe 21:1371-1383

46. Vadassery J, Ranf S, Drzewiecki C, Mithöfer A, Mazars C, Scheel D, Lee J, Oelmüller R (2009) A cell wall extract from Piriformospora indica promotes growth of Arabidopsis seedlings and induces intracellular calcium elevation in roots. Plant $\mathrm{J}$ 59:193-206

47. Vadassery J, Tripathi S, Prasad R, Varma A, Oelmüller R (2009) Monodehydroascorbate reductase 2 and dehydroascorbate reductase 5 are crucial for a mutualistic interaction between 
Piriformospora indica and Arabidopsis. J Plant Physiol 166:1263-1274

48. Varma A, Verma S, Sudha, Sahay N, Buttehorn B, Franken P (1999) Piriformospora indica, a cultivable plant-growth-promoting root endophyte. Appl Environ Microbiol 65:2741-2744

49. Varma A, Singh A, Sudha M, Sahay NS, Sharma J, Roy A, Kumari M, Rana D, Thakran S, Deka D, Bharti K, Hurek T, Blechert O, Rexer KH, Kost G, Hahn A, Maier W, Walter M, Strack D, Kranner I (2001) Piriformospora indica: a cultivable mycorrhiza-like endosymbiotic fungus. In: Hock B (ed) The Mycota IX. Springer-Verlag, Berlin, Germany, pp 125-150

50. Varma A, Tripathi S, Prasad R, Das A, Sharma M, Bakshi M, Arora M, Rastogi K, Agrawal A, Kharkwal AC, Tsimilli-Michael M, Strasser RJ, Bagde US, Bisaria VS, Upadhyaya CP, Malla R, Kost G, Joy K, Sherameti I, Chen Y, Ma J, Lou B, Oelmüller R (2012) The symbiotic fungus Piriformospora indica: update. In: Hock B (ed) The Mycota XXL. Springer, Berlin, in press

51. Varma A, Fekete A, Srivastava A, Saxena AK, Frommberger M, Li D, Gschwendter S, Sheramati I, Oelmueller R, Kopplin PS, Tripathi S, Hartmann A (2012) Inhibitory interactions of rhizobacteria with the symbiotic fungus Piriformospora indica. In: Varma A, Oelmueller R (eds) Sebacinales. Springer, Berlin, in press

52. Verma S, Varma A, Rexer K, Hassel A, Kost G, Sarbhoy A, Bisen P, Bütehorn B, Franken P (1998) Piriformospora indica, gen. et sp. nov., a new root-colonizing fungus. Mycologia 90:896-903

53. Waller F, Achatz B, Baltruschat H, Fodor J, Becker K, Fischer M, Heier T, Huckelhoven R, Neumann C, von Wettstein D et al
(2005) The endophytic fungus Piriformospora indica reprograms barley to salt-stress tolerance, disease resistance, and higher yield. Proc Natl Acad Sci USA 102:13386-13391

54. Weiss M, Selosse MA, Rexer KH, Urban A, Oberwinkler F (2004) Sebacinales: a hitherto overlooked cosm of heterobasidiomycetes with a broad mycorrhizal potential. Mycol Res 108:1003-1010

55. Weiss M, Sýkorová Z, Garnica S, Riess K, Martos F, Krause C, Oberwinkler F, Bauer R, Redecker D (2011) Sebacinales everywhere: previously overlooked ubiquitous fungal endophytes. PLoS ONE 6:e16793

56. Yadav V, Kumar M, Deep DK, Kumar H, Sharma R, Tripathi T, Tuteja N, Saxena AK, Johri AK (2010) A phosphate transporter from the root endophytic fungus Piriformospora indica plays a role in phosphate transport to the host plant. J Biol Chem 285:26532-26544

57. Zuccaro A, Basiewicz M, Zurawska M, Biedenkopf D, Kogel K-H (2009) Karyotype analysis, genome organization, and stable genetic transformation of the root colonizing fungus Piriformospora indica. Fungal Genet Biol 46:542-550

58. Zuccaro A, Lahrmann U, Ldener UG, Langen G, Pfiffi S, Biedenkopf D, Wong P, Samans B, Grimm C, Basiewicz M, Murat C, Martin F, Kogel KH (2011) Endophytic life strategies decoded by genome and transcriptome analyses of the mutualistic root symbiont Piriformospora indica. PLoS Pathog 7:e1002290 